\title{
Um olhar e muitas perguntas sobre os exilados transatlânticos, suas histórias conectadas e paralelas
}

\author{
Marco Antonio Villela Pamplona* \\ Pontifícia Universidade Católica do Rio de Janeiro \\ Rio de Janeiro - Rio de Janeiro - Brasil
}

Difícil falarmos de exílio e de exilados, sem qualquer menção a Edward Said, brilhante professor palestino da Universidade de Columbia, que cresceu no Egito e nos Estados Unidos. Sua "condição política" de exilado, ou do indivíduo "sem lugar" que continua a estar em desacordo tanto com o mundo que o rejeitou como com aquele que abraçou, parecia perene e só foi encerrada com o seu falecimento em 2003.

Said deixou-nos uma relíquia, o texto "Reflections on Exile", cuja primeira versão apareceu em 1984 na Harpers Magazine. Nele, inicia uma densa discussão sobre essa "condição de perda" bastante particular - o exílio - descrito como produto de uma "fratura forçada",

* Professor do Programa de Pós-Graduação e Graduação do Departamento de História da PUC-Rio. $\mathrm{PhD}$ em História pela Columbia University in the City of New York. Coordenador do Núcleo de Estudos Interdisciplinares Ibero-Americanos da PUG-Rio. E-mail: pamplona@puc-rio.br.

1 Este texto foi publicado inicialmente com o título "The Mind of Winter: Reflections on life in exile" na Harpers Magazine 260 (161), 1984. Porém, estaremos utilizando aqui, em nossas citações, a edição de 2002 da Cambridge: Edward Said. "Reflections on Exile" in Reflections on Exile and Other Essays, Cambridge. Mass: Harvard UP, 2002, pp 137-49. 
criadora de uma ruptura não mais sanada ou refeita entre um ser humano e seu lugar de origem.

$\mathrm{O}$ exilado, impedido literal e legalmente de voltar à terra natal, ou ao lugar onde sente que pertence, pode sucumbir a condições negativas e desenvolver em sua essência, inclusive, aquela enorme tristeza que nunca conseguirá superar. Este sentimento de tristeza, para Said, é comparado à morte -"like death without death's ultimate mercy". ${ }^{2}$

Mesmo nessas condições adversas, sua mente inquieta via que o exílio - não o escolhido, mas aquele que acontece a alguém, ou aquele no qual se pode nascer - longe de constituir privilégio, podia tornarse, porém, uma "alternativa" para se reagir às instituições de massa que, desde o início do século XX, vinham dominando de forma avassaladora a vida moderna. Said, assim, endossava uma crítica que antes Adorno também fizera a esse mundo moderno, tido como "administrado", caracterizado pela vida submetida a "formas prontas" e "lares pré-fabricados" ". Neste mundo, palavras, pensamentos e objetos eram transformados em meras mercadorias. Salientava que era preciso se opor a isso e, para tal, passava a ser importante "ficar longe do lar", para olhá-lo mais criticamente. Este certo ethos, lembra-nos Said, é o mesmo que permanece vivo na condição de exílio. Pois, quando exilados e exiladas se recusam a permanecer sentados tratando de feridas que sabem não cicatrizarão, percebem que há coisas a serem aprendidas. Para isso, diz-nos, devem "cultivar uma subjetividade escrupulosa (nem indulgente nem arredia)" .

Ainda que sofrida, Said considera a situação em que se encontra o exilado bastante valiosa, do ponto de vista moral. Ela se torna propícia para a aquisição de uma certa distância crítica em relação às distintas identidades culturais e para dar início a uma oposição incansável às mais diversas ortodoxias. Nessas circunstâncias, pode-se com mais facilida-

Ibid., pp 137 e 138. "It is an unhealable rift forced between a human being and a native place, between the self and its true home", (...) "a crippling sorrow of estrangement".

Veja-se Theodor Adorno. Minima Moralia, apud Said, Ibid., p. 147.

4 Ibid., p 147. 
de perceber-se a virulência do nacionalismo e, igualmente, denunciar a sua associação estreita com a própria condição do exílio moderno ${ }^{5}$.

$\mathrm{O}$ nacionalismo incensa a condição de pertença a um lugar, um povo, uma herança. Sua retórica reafirma, via de regra, a comunidade linguística, a cultura e os costumes - estes são identificados ao "lar" de cada um. $\mathrm{O}$ exilado, necessariamente, se encontra fora do aconchego desse "lar" e de suas lealdades paroquiais. Nas palavras de Said: "Exilados veem os não exilados com ressentimento. Eles pertencem ao seu lugar, (...) o exilado está sempre fora do lugar. Como será nascer num lugar, poder ficar e viver nele, saber que você pertence a ele mais ou menos para sempre ${ }^{6 "}$ ? Assim, o exílio acaba se tornando um oposto necessário ao nacionalismo. Ambos passam a se retroalimentar com frequência, e cada um informa e constitui a condição do outro.

A partir dessas considerações gerais sobre o tema do exílio, começamos a refletir e indagar sobre a particular condição dos exilados-migrantes de que trata Sylvie Aprile. De que forma o exílio foi vivenciado na segunda metade do século XIX, nas sociedades das Américas? Os países de adoção - Estados Unidos, Brasil e Argentina, no caso do presente estudo - ofereceram aos indivíduos deslocados similares condições de existência? Ou foram elas bastante diferenciadas? De que forma puderam moldar as experiências de Marie-Antoine Campdoras, Victor Frond e Herminie Cadolle? A condição de imigrantes acabou ajudando-os? Os prejudicou? Em que medida cada um desses exilados pode dar uma "contribuição" para a sociedade que os recebeu? Foram fundamentais as suas qualificações e talentos? Como cada

5 Pensamos que essa associação com o estado-nação predominou sobretudo durante o "longo século XIX" (isto é, de fins do XVIII às duas primeiras décadas do XX). Ela certamente esteve ausente em exílios passados que haviam sido mais característicos de outros tempos históricos - como, por exemplo, a prática do banimento entre distintos povos da antiguidade ou o exílio voluntário da peregrinação medieval. E, em fins o século XX e início do XXI, começou a ser transformada a medida que novos deslocamentos forçados de populações, em meio às muitas guerras de extermínio do mundo crescentemente globalizado, começaram a ser articulados fortemente à noção mais contemporânea dos "exilados-refugiados" dos nossos dias.

6 Said, op. cit., p 143. 
um tirou partido desse deslocamento não apenas geográfico, mas marcadamente cultural e social? Pode-se dizer que as mobilidades inicialmente escolhidas e o que eles efetivamente vivenciaram nas Américas corresponderam de algum modo? Em qualquer dos casos, uma coisa sabemos: as respectivas trajetórias de vida desses exilados-migrantes modificaram-se profundamente.

Vejamos os caminhos trilhados pelos três para chegar Américas. Em que pese ao cuidadoso estudo de Sylvie Aprile, o material reunido sobre essas histórias de vida (excetuando-se, talvez, os dados relativos à biografia de Victor Frond) permanece escasso, permitindo-nos considerações muito parciais e apenas tentativas de resposta às perguntas acima.

Acompanhemos um pouco do relato da Autora sobre a saga desses três fascinantes indivíduos - dois homens e uma mulher - fugidos para as Américas em diferentes momentos da França novecentista, mas sempre marcados por profunda convulsão política. O primeiro deles o tumultuado ano de 1852, corresponde ao ocaso da Segunda República, a de 1848. É sucedida pelo Segundo Império, com a coroação de Luís Bonaparte como Napoleão III no mesmo ano. O outro momento importante de convulsão política, correspondeu, mais para o final do século, à experiência da Comuna de Paris (1871), paralelamente ao trágico desfecho da Guerra Franco-Prussiana. Com o fim do Império napoleônico, abriu-se caminho para a Terceira República, iniciada em 1872.

$\mathrm{O}$ ano de 1852 ajuda-nos a compreender o mundo que Marie-Antoine Campdoras e Victor Frond, cada qual com seu motivo, quiseram deixar para trás. Republicanos convictos, não lhes faltaram motivos para querer deixar a França após o golpe de Luís Bonaparte.

Marie-Antoine Campdoras, cirurgião da marinha, já havia deixado o hospital onde trabalhava em Toulouse e lançara-se ao mar desde 1848. Embarcando em navios diferentes, vagou pela costa da África até 1851. No ano seguinte, decidiu-se pelo exílio. As razões dessa escolha estão registradas em carta enviada desde a América a Noël Blanche, seu compatriota, também republicano. Em poucas linhas, mostrou-lhe claramente o descontentamento e decepção com o cenário 
político em seu país. ${ }^{7}$ Uma vez chegado aos Estados Unidos, teve de exercer para além do seu ofício de praxe, algumas outras habilidades para sobreviver. Foi ora cirurgião, ora professor de francês e espanhol nas diferentes cidades por onde passou. Inicialmente viveu na Cidade de Nova York, mas andou também por outras cidades da Louisiana e do Missouri, antes de chegar à Cidade de Topeka, no Kansas, onde estabeleceria a sua residência mais definitiva. Ficou ali pelas próximas décadas, casou-se com uma americana, constituiu família e acabou tornando-se fazendeiro. Pareceu ter conseguido se envolver e adaptar-se o suficiente ao modo de vida da sociedade receptora, ficando um bom tempo longe da França. A ela só fez uma única viagem em 1880, um ano apenas antes de sua morte, movido pela necessidade de tratar sua doença na Europa. É notável o fato de que Campdoras pode manter-se ativo em sua militância no país receptor. Adaptando suas fortes convicções democráticas e patrióticas às circunstâncias locais, envolveu-se na luta do Sul. O advento da Guerra Civil a partir de 1861 lhe permitiu voltar à vida militar. Em 1862, alistou-se no Second Regiment of Kansas Home Guards, também chamado de Indian Regiment, para a defesa da fronteira. Finda a guerra, diz-nos Sylvie Aprile, tornou-se militante do movimento dos Granges. Em 1873, Campdoras aderiu aos Community Grange para resistir, em conjunto com os demais pequenos fazendeiros e produtores locais, aos extorsivos preços impostos pelas ferrovias para o transporte dos produtos rurais para as cidades.

Bem diferente foi a partida de Victor Frond, naquele mesmo ano de 1852, para uma outra parte das Américas onde também vigorava a "peculiar instituição" escravidão - o Império do Brasil. Em sua pátria, Frond fora subtenente e servira até 1851 na Caserna da 4a

7 Sylvie Aprile reproduz em seu trabalho algumas linhas dessa carta, expressando esta desilusão de Campdoras: "O triste France, pays des lâches, je ne sais si j’ai pour toi de l'amour ou de la haine! Hommes de l'ancien, du vieux monde, votre temps est fini; vous êtes en décadence. La France, qui, dit-on, est le cœr et le cerveau de l'Europe, est morte. Il n’y a plus rien à espérer d'elle, et sa résurrection est impossible ! C'est ici, c'est en Amérique qu'est passée l'âme de l'humanité". Sylvie Aprile, ${ }^{2}$ Exilé(e)s et migrant(e)s transatlantiques: histoires entremêlées, historiographies parallèles", p 10 (cf. texto mimeo recebido para a palestra que proferiu em Londrina, 2016). 
Companhia do Batalhão de Bombeiros de Paris. Feito prisioneiro com o golpe de Luís Bonaparte, amargou uma breve prisão na Argélia até conseguir escapar para a Inglaterra. Uma vez no exílio, juntou-se aos demais republicanos franceses e retomou suas atividades de militante. Viajou à Espanha e Portugal e neste último país, em Lisboa, iniciou seu contato com a fotografia, uma nova arte que começava a se desenvolver com força naquela segunda metade do século. Chegou ao Brasil em 1852 e logo abriu seu estúdio de fotografia no Rio de Janeiro. O fato de ter trazido boas referências - em especial, lembra Sylvie Aprile, cartas de apresentação escritas por Victor Hugo - deve ter facilitado sua mobilidade na corte pedrina. Frond foi prontamente aceito no estreito círculo do Imperador e tornou-se o primeiro fotógrafo da família imperial. Sua breve estadia de sete anos no Brasil foi bastante proveitosa. Ainda em 1858, fez vir para o Rio de Janeiro, às suas próprias custas, um outro exilado e compatriota, o jornalista republicano Charles Ribeyrolles, que também tivera contato com Victor Hugo quando do exílio em Jersey. Juntos, Frond e Ribeyrolles iriam produzir o livro-álbum intitulado Le Brésil Pittoresque ou O Brazil Pittoresco. Esta detalhada e bonita obra com as belas fotografias do primeiro e as elegantes narrativas do segundo, foi publicada pela Typographia Nacional, em 1859. Tornada sucesso, obteve uma divulgação maior ainda quando foi publicada novamente na França, pela Imprimerie Lemercier, em $1861^{8}$.

Frond decidiu voltar ao seu país já em 1859, logo após a concessão da anistia. Lá, continuou e ampliou suas atividades de fotógrafo e de editor e publicou duas outras obras com sucesso: Le Panthéon des illustrations françaises au 19ème siècle (1863) e Actes et historie du concile œcuménique de Rome (1869) ${ }^{9}$. Beneficiado igualmente pela anistia, Ribeyrolles, en-

8 Nossa referência aqui é a edição bilíngue publicada pela Typographia Nacional, a qual pode ser consultada no acervo digital da Biblioteca Nacional, sob os títulos: Brazil pittoresco [Livro]: Historia, descripções, viagens, instituições, colonisação. Acompanhado por album de vistas, panoramas, paisagens, costumes, etc., etc., Tomos 1, 2 e 3; e Brazil pittoresco [Iconográfico]: album de vistas, panoramas, monumentos..., 1861.

9 Aprile, op. cit., p 14. 
tretanto, não teve a mesma sorte. No mês de junho de 1860, ficou doente e morreu de febre amarela pouco antes do seu embarque de volta.

Um segundo momento de acirrada convulsão política na França que produziu novos exilados foi o da repressão à Comuna de Paris, em 1871. Herminie Cadolle pertencia a esse mundo. Na sua biografia de antes do exílio é sempre apresentada como estando fortemente envolvida com a sublevação dos communards no final da Guerra franco-prussiana. Operária em fábrica de roupas íntimas femininas, militante tal qual o marido e o filho, Cadolle participa intensamente dos acontecimentos durante esse período da resistência parisiense. Diz-nos ainda Sylvie Aprile, ela integrou um dos primeiros movimentos autoproclamados feministas - L'Union des femmes pour la defense de Paris e les soins des blesses ${ }^{10}$. Lutando pelo fim do Império e por uma República democrática, foi feita prisioneira por seis meses em Rouen. Quando libertada, logo retornou à militância, atuando nos Comitês de Apoio aos condenados da Comuna que haviam sido deportados para a Nova Caledônia.

Surpreendeu-nos, pois, o fato do exílio de Cadolle só ter se dado muito tempo depois, no início do ano de 1887, quando o cenário político não mais representava uma ameaçava aos republicanos. Fora ela para a Argentina mais como emigrante e menos como exilada? Fugindo aos padrões femininos do século XIX, também surpreendeu-nos o fato dela ter decidido ir sozinha (sem o marido ou o filho) tentar a vida nas Américas? Infelizmente, tem-se pouquíssimas informações sobre a Herminie Cadolle desde sua chegada ao novo país, lembra-nos Sylvie Aprile. O seu retorno definitivo à França só se daria vinte e três anos depois, e em condições radicalmente inversas às de sua saída. Cadolle volta como uma bem sucedida empresária no ramo da produção e venda de lingeries. Essa radical metamorfose a torna, possivelmente, a mais curiosa das três personagens estudadas. Pois, enfatiza Sylvie Aprile, além de comerciante bem sucedida, Cadolle mostrou-se extre-

${ }^{10}$ Ibid., p 18. A autora menciona, inclusive, a amizade de Herminie Cadolle com Louise Michel, a importante feminista e anarquista dos anos da Comuna. 
mamente inovadora para a época, mesmo entre os seus novos pares. No seu retorno a Paris, em 1910, fez-se proprietária de um ateliê e de uma loja e muito rapidamente iniciou um sistema de venda por catálogo dos seus famosos corselets-gorges. Passou a poder atender, desse modo, não apenas mais gente, mas aquelas pessoas de cidades bastante distantes como Buenos Aires, Londres, Nova York e São Petersburgo. Paralelamente ao aumento das vendas, registra a própria Sylvie Aprile, os ateliês de Cadolle se multiplicaram, ce chegaram a empregar cerca de 200 ou mais operários ${ }^{11}$.

Surgem muitas perguntas e comparações quando nos debruçamos sobre as histórias conectadas e paralelas dos três emigrados-exilados franceses. Primeiramente, não podemos deixar de nos perguntar como Herminie Cadolle conseguiu e mover com tanta destreza na sociedade argentina de fins do novecentos. Obteve ela alguma ajuda das redes locais dos imigrantes europeus anarquistas ou socialistas que a precederam na Cidade de Buenos Aires? Como a mobilidade e ascenção social que ela conquistara foi absorvida pela cultura portenha extremamente machista da época ? Teria sido ela também vítima da visão depreciativa, quando não xenófoba, que os setores mais conservadores da oligarquia bonaerense conferiam aos numerosos imigrantes europeus pobres arribados nas duas últimas décadas do século XIX? Afinal, não estamos tratando daquela Argentina que dobrara espetacularmente a sua população na virada do século, em grande parte devido à imigração continuada de europeos naqueles anos. Segundo o Terceiro Censo Nacional, o de 1914, o número de estrangeiros ultrapassava em muito o dos nascidos no país, e isso não apenas em Buenos Aires, mas também nas cidades de Rosario e Bahía Blanca ${ }^{12}$.

Diferentemente, Marie-Antoine Campdoras não chegou a "fazer a América" nem viveu a "rugs-to-riches story" de Herminie Cadolle.

\footnotetext{
${ }^{11}$ Ibid, p. 19.

${ }^{12}$ David Rock, Argentina, 1516-1987. From Spanish Colonization to Alfonsin, CA: U. California Press, 1987, p 167 e Fernando Devoto, Historia de la inmigración en Argentina, B.A., Editorial Sudamericana, 2003, pp 40 e 41.
} 
Mas, sua condição de exilado não o impediu de fazer o que no seu entendimento pode ter sido uma sua "contribuição" importante ao país de adoção, maior mesmo do que a que dera no passado à França, de onde saíra em 1852, com a chegada de Napoleão III ao poder. Penso que seu esforço de assimilação somado às qualificações profissionais que trouxe consigo o tornaram especialmente "dinâmico" na nova sociedade. Sua participação na Guerra Civil fora considerada patriótica pelos locais. $\mathrm{O}$ fato de lutar no exército sulino, ainda que pudesse soar bastante antidemocrático para os padrões franceses identificados à Republica de 1848, ganhou ressignificações, ao que parece. E, apesar da manutenção do interesse e afeição à terra natal, o longo tempo ausente acabou enfraquecendo a sua decisão "de voltar algum dia". Seu retorno acabou se dando mesmo por motivo de doença, em 1880, apenas um ano antes de morrer. Postumamente, sua viúva receberia um benefício pecuniário a título de reconhecimento pela lei de reparação nacional de 1881. Mas, teria isso importado para Campdoras?

Parece-nos que a contribuição maior do estudo de Sylvie Aprile, ao entremear as vidas desses personagens na narrativa que ora submete ao nosso olhar, é da desconstrução do exílio como situação meramente ou exclusivamente objetiva. Seu estudo reafirma, diversamente, a ideia de que o exílio é sobretudo uma experiência que cada exilado vive necessariamente de maneira individual e em função de uma sua subjetividade ${ }^{13}$.

Seu trabalho nos permite a romper com aquelas categorias excessivamente normativas ou com os eventuais ideal-tipos que costumam ser construídos para se tratar do exilado ${ }^{14}$. As três personagens do texto de Sylvie Aprile são exemplos claros de como os seres humanos respondem diferentemente à condição de banimento e à vida no exílio. Como isso é feito sempre de acordo com a natureza do exílio desta ou daquela pessoa. Como, enfim, pesam de forma substantiva, as cir-

\footnotetext{
${ }^{13}$ Bruno Groppo, "Os Exílios europeus no século XX", Diálogos, DHI/UEM, v. 6, 2002., p 78. Ver também Edward Said. Out of Place. London: Granta, 1999.

${ }^{14}$ Michael Böss. "Theorizing Exile”, In: Böss, Nordin e Olinder (eds.) Re-Mapping Exile. Realities and Metaphors in Irish Literature and History. Aarhus, DNK: Arhus U Press, 2005., pp 15-46.
} 
cunstâncias particulares em que cada um(a) se encontra. Os recursos pessoais, espirituais, sociais e culturais do(a) próprio(a) exilado(a) são o que acabam contando efetivamente. Capacitam-no a melhor avaliar sua sorte ou destino, a adotar um topos que poderá lhe trazer conforto e até dar-lhe a possibilidade de transformar qualquer lugar em sua casa. O exílio, assim, poderá tornar-se menos insuportável, com menos espaço para a melancolia, raiva ou alienação.

Edward Said veria nessa recuperação da subjetividade um importante ponto de partida para se realizar a missão intelectual do exilado. Com a consciência de que todos os "lares" ou "pátrias" são provisórios num mundo secular e contingente, a existência de fronteiras e barreiras que nos encerram em territórios ditos "familiares" também podem se tornar prisões. Este cenário só empiora, quando tais territórios são defendidos de forma irracional e sem necessidade muitas vezes, pelos estados-nação modernos que os produzem. Cabe aos exilados cruzar essas fronteiras, rompendo as barreiras de pensamentos e de experiências. E, mais uma vez citando Adorno, o "exilado permanente" de mente inquieta conclui: "it's part of morality not to be at home in one's home."

Recebido: 10/08/2017 - Aprovado: 18/09/2017

${ }^{15}$ Said, op. cit., p 147. 